УДК 616.314.001.6-089.23-76

DOI 10.18413/2687-0940-2020-43-2-237-248

\title{
ИЗУЧЕНИЕ РАЗМЕРНОЙ ТОЧНОСТИ ВНУТРЕННЕГО ПРИЛЕГАНИЯ КАРКАСОВ ИСКУССТВЕННЫХ КОРОНОК ИЗ ДИСИЛИКАТА ЛИТИЯ, ИЗГОТОВЛЕННЫХ С ПОМОЩЫЮ ТРАДИЦИОННЫХ И ЦИФРОВЫХ ТЕХНОЛОГИЙ
}

\section{STUDY OF THE DIMENSIONAL ACCURACY OF THE INTERNAL FIT OF THE FRAMES OF ARTIFICIAL CROWNS MADE OF LITHIUM DISILICATE USING TRADITIONAL AND DIGITAL TECHNOLOGIES}

\author{
Е.Н. Жулев ${ }^{1}$, Ю.А. Вокулова ${ }^{2}$ \\ E.N. Zhulev ${ }^{1}$, Y.A. Vokulova ${ }^{2}$ \\ ${ }^{1}$ Приволжский исследовательский медицинский университет, \\ Россия, 603950, БОКС-470, г. Нижний Новгород, пл. Минина и Пожарского, д. 10/1 \\ ${ }^{2}$ Федеральное государственное казенное учреждение «Поликлиника № 2 \\ Федеральной таможенной службы России», \\ Россия, 603098, Нижний Новгород, ул. Артельная, д. 2 \\ ${ }^{1}$ Privolzhsky Research Medical University, \\ 10/1 Minin and Pozharsky, BOX-470, Nizhny Novgorod, 603950, Russia \\ ${ }^{2}$ Federal state official institution «Polyclinic No. 2 of the Federal customs service of Russia», \\ 2 Artelnaya St., Nizhny Novgorod, 603098, Russia \\ E-mail: vokulova@rambler.ru
}

\begin{abstract}
Аннотация
Целью исследования было изучение качества внутреннего прилегания каркасов искусственных коронок из дисиликата лития, изготовленных с применением 3D-принтера Asiga Max UV, $\mathrm{CAD} / \mathrm{CAM}$-системы $\mathrm{KaVo}$ ARCTICA, по цифровым изображениям экспериментальной модели, полученным внутриротовым лазерным сканером iTero Cadent и каркасов искусственных коронок, изготовленных методом прессования литьевой керамики. Величину внутреннего прилегания каркасов искусственных коронок измеряли в компьютерной программе Image $\mathbf{J}$ по фотографиям шлифов силиконовых реплик внутреннего прилегания, сделанным с помощью операционного микроскопа Leica M320 под 40-кратным увеличением. Для статистического анализа полученных данных применяли непараметрический Н-критерий Краскела - Уоллиса и W-критерий Манна Уитни. Было выявлено, что среднее значение величины цементного зазора между культей зуба и каркасом искусственной коронки из дисиликата лития, изготовленным в CAD/CAM системе KaVo ARCTICA из заготовок E.max CAD, составляет 50,00 $\pm 2,559$ мкм, из заготовок беззольного полимерного материала KaVo ARCTICA C-Cast - 50,54 \pm 0,5957 мкм. Среднее значение величины цементного зазора между культей зуба и каркасом искусственной коронки, изготовленным с применением 3D-принтера Asiga Max UV, составляет 50,27 $\pm 1,218$ мкм. Среднее значение величины цементного зазора между культей зуба и каркасом искусственной коронки, изготовленным по традиционному методу прессования без использования цифровых технологий, составило $120,7 \pm 12,86$ мкм. На основании полученных данных сделан вывод, что современные цифровые технологии позволяют изготавливать каркасы искусственных коронок из дисиликата лития с меньшей величиной цементного зазора, т. е. с существенно большей точностью в отличие от каркасов, полученных с помощью традиционной технологии прессования $(\mathrm{p}<0,05)$.
\end{abstract}

\footnotetext{
Abstract

The aim of the study was to study the quality of the internal fit of the frames of artificial crowns made of lithium disilicate made using the 3D printer Asiga Max UV, CAD/CAM-system KaVo ARCTICA, using digital images of the experimental model obtained by the intraoral laser scanner iTero Cadent and the
} 
frames of artificial crowns made by pressing molding ceramics. The size of the internal fit of the artificial crown frames was measured in the Image $\mathbf{J}$ computer program from photos of internal fit silicone replicas made with a Leica M320 operating microscope at 40-fold magnification. For statistical analysis of the obtained data, the nonparametric H-Kruskel-Wallis test and the W-Mann-Whitney test were used. It was found that the average value of the cement gap between the tooth stump and the frame of the artificial crown made of lithium disilicate made in the KaVo ARCTICA CAD/CAM system from E. max CAD blanks is 50,00 $\pm 2,559$ microns, from the blanks of the ash-free polymer material KaVo ARCTICA C-Cast $-50,54 \pm 0,5957$ microns. The average value of the cement gap between the stump of the tooth and the frame of the artificial crown made using the 3D printer Asiga Max UV is 50,27 $\pm 1,218$ microns. The average value of the cement gap between the stump of the tooth and the frame of the artificial crown, made using the traditional method of pressing without the use of digital technologies, was $120,7 \pm 12,86$ microns. Based on the data obtained, it is concluded that modern digital technologies allow manufacturing artificial crown frames made of lithium disilic with a smaller size of the cement gap, i. e. with significantly greater accuracy in contrast to frames obtained using traditional pressing technology $(\mathrm{p}<0,05)$.

Ключевые слова: цифровые оттиски, CAD/CAM, внутриротовой сканер, стереолитография, 3D-печать, внутреннее прилегание несъемных протезов, искусственные коронки из дисиликата лития, цифровые технологии в стоматологии.

Keywords: digital impressions, CAD/CAM, intraoral scanner, stereolithography, 3D printing, internal fit of fixed prostheses, lithium disilicate crowns, digital technologies in dentistry.

\section{Введение}

Традиционные методы изготовления цельнокерамического зубного протеза из дисиликата лития - это серия процессов, которая включает получение оттисков, изготовление гипсовых моделей, создание восковой репродукции протеза и прессование керамических заготовок [Маркскорс, 2007; Розенштиль, 2010; Смит, Хоу, 2010]. Однако при применении традиционной технологии риск потери точности готовых протезов из дисиликата лития может возрасти из-за физико-химических свойств используемых материалов (усадка оттискных материалов, расширение гипса) и мануальных навыков зубного техника [Брикс, 2014; Лебеденко и др., 2016]. Кроме того, метод прессования литьевой керамики занимает достаточно большой промежуток времени [Цельнокерамические реставрации..., 2010]. Для устранения этих недостатков в стоматологической практике были внедрены автоматизированные системы моделирования и производства зубных протезов - CAD/CAM системы, 3D-принтеры, внутриротовые сканеры [Ряховский, 2010; Вокулова, Жулев, 2016а, б; Наумович, Разоренов, 2016; Шустова, Шустов, 2016; Вокулова, 2017; Вокулова, Жулев, 2017; Карякин, Горбатов, 2019; Dawood et al., 2015]. Для оценки качества несъемных протезов, изготовленных с применением современных цифровых технологий, важно иметь представление о плотности их прилегания к культе опорного зуба [Арутюнов и др., 2006; Massironi et al., 2007; Ng et al., 2014]. Научных публикаций, посвященных изучению качества внутреннего прилегания каркасов искусственных коронок, изготовленных из дисиликата лития, полученных с применением современных цифровых методов, явно недостаточно, что и явилось обоснованием проведения данного исследования.

Цель исследования - изучить качество внутреннего прилегания каркасов искусственных коронок из дисиликата лития, изготовленных с применением 3D-принтера Asiga Max UV, CAD/CAM-системы KaVo ARCTICA, по цифровым изображениям экспериментальной модели, полученным внутриротовым лазерным сканером iTero Cadent, и искусственных коронок, изготовленных методом прессования литьевой керамики. 


\section{Материалы и методы исследования}

Для изучения внутреннего прилегания каркасов искусственных коронок из дисиликата лития E.max (Ivoclar Vivadent, Лихтенштейн), изготовленных с помощью традиционных и цифровых технологий, нами была разработана специальная схема проведения исследования (рис. 1), в которой использована экспериментальная модель (рис. 2a) с подготовленным под искусственную коронку зубом с циркулярным уступом в виде желоба.

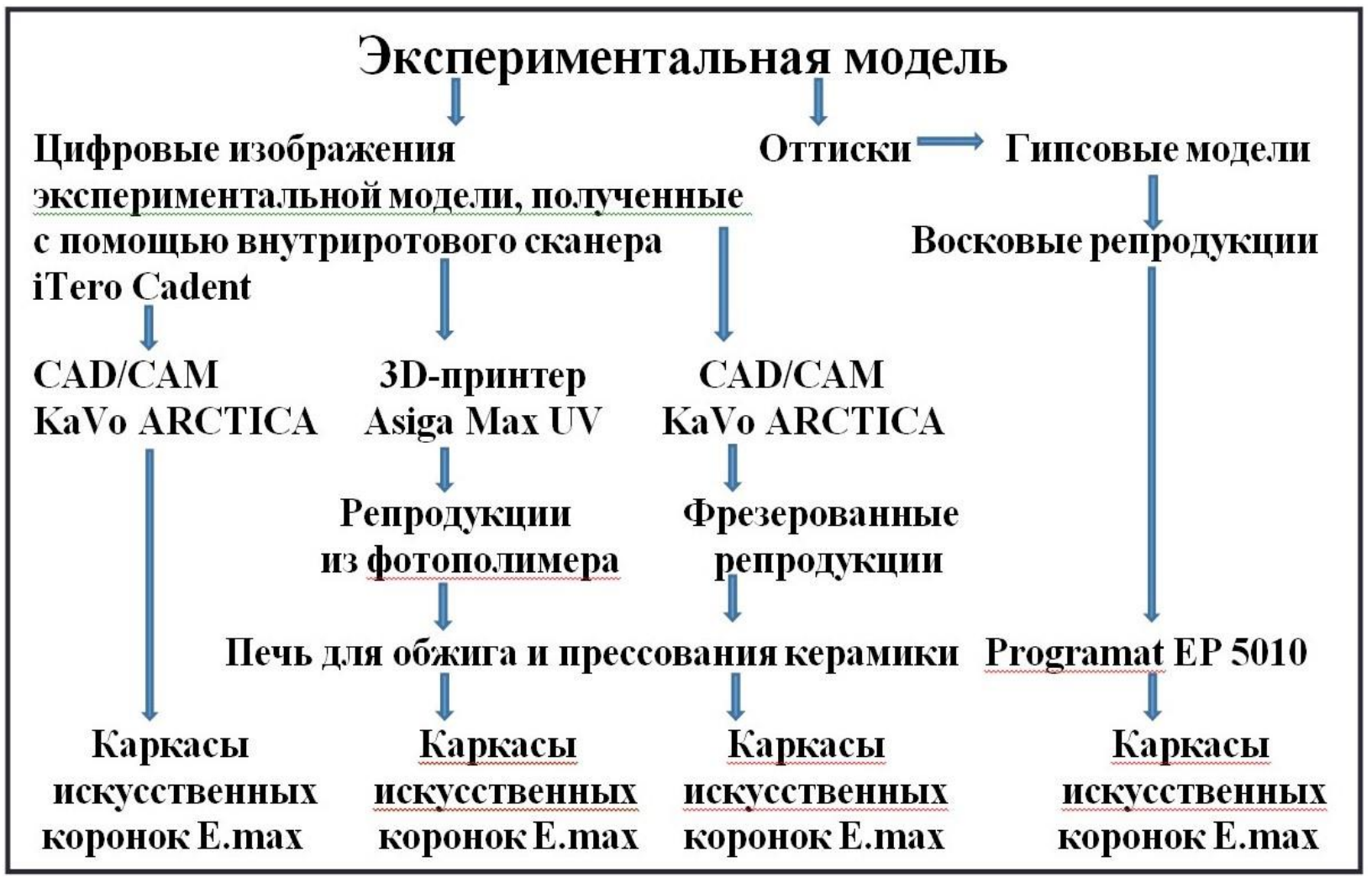

Рис. 1. Схема проведения эксперимента

Fig. 1. Scheme of the experiment

На первом этапе были получены 10 цифровых изображений экспериментальной модели с помощью внутриротового лазерного сканера iTero Cadent (США). В программном обеспечении DentalCAD 2.2 Valletta проводили моделирование 10 каркасов искусственных коронок.

На втором этапе в фрезерно-шлифовальном станке KaVo ARCTICA Engine из заготовок дисиликата лития E.max CAD были изготовлены 10 каркасов искусственных коронок (рис. 2б), из заготовок беззольного полимерного материала KaVo ARCTICA C-Cast были получены 10 репродукций каркасов искусственных коронок (рис. 2д). Далее с помощью 3D-принтера Asiga Max UV методом стереолитографии (SLA) были изготовлены 10 репродукций каркасов искусственных коронок (рис. 2c) из фотополимерного материала Freeprint cast UV (DETAX, Германия). Затем методом прессования с помощью печи для обжига керамических заготовок Programat EP 5010 были получены из изготовленных ранее в CAD/CAM-системе и 3D-принтере репродукций 20 каркасов искусственных коронок из дисиликата лития IPS e.max.

На третьем этапе с экспериментальной модели были получены 10 двухслойных одноэтапных А-силиконовых оттисков (Express STD, Express XT Regular Body, 3M ESPE, США) и изготовлены разборные модели из высокопрочного гипса Fujirock (GC, Япония). Далее создавали восковые репродукции каркасов искусственных коронок методом погру- 
жения до получения необходимой толщины, чтобы воск полностью покрывал культю вместе с уступом. Моделировали литники, формовали в опоку, выплавляли воск и изготавливали с помощью печи для прессования и обжига керамических заготовок Programat EP5010 10 каркасов искусственных коронок из дисиликата лития IPS e.max.
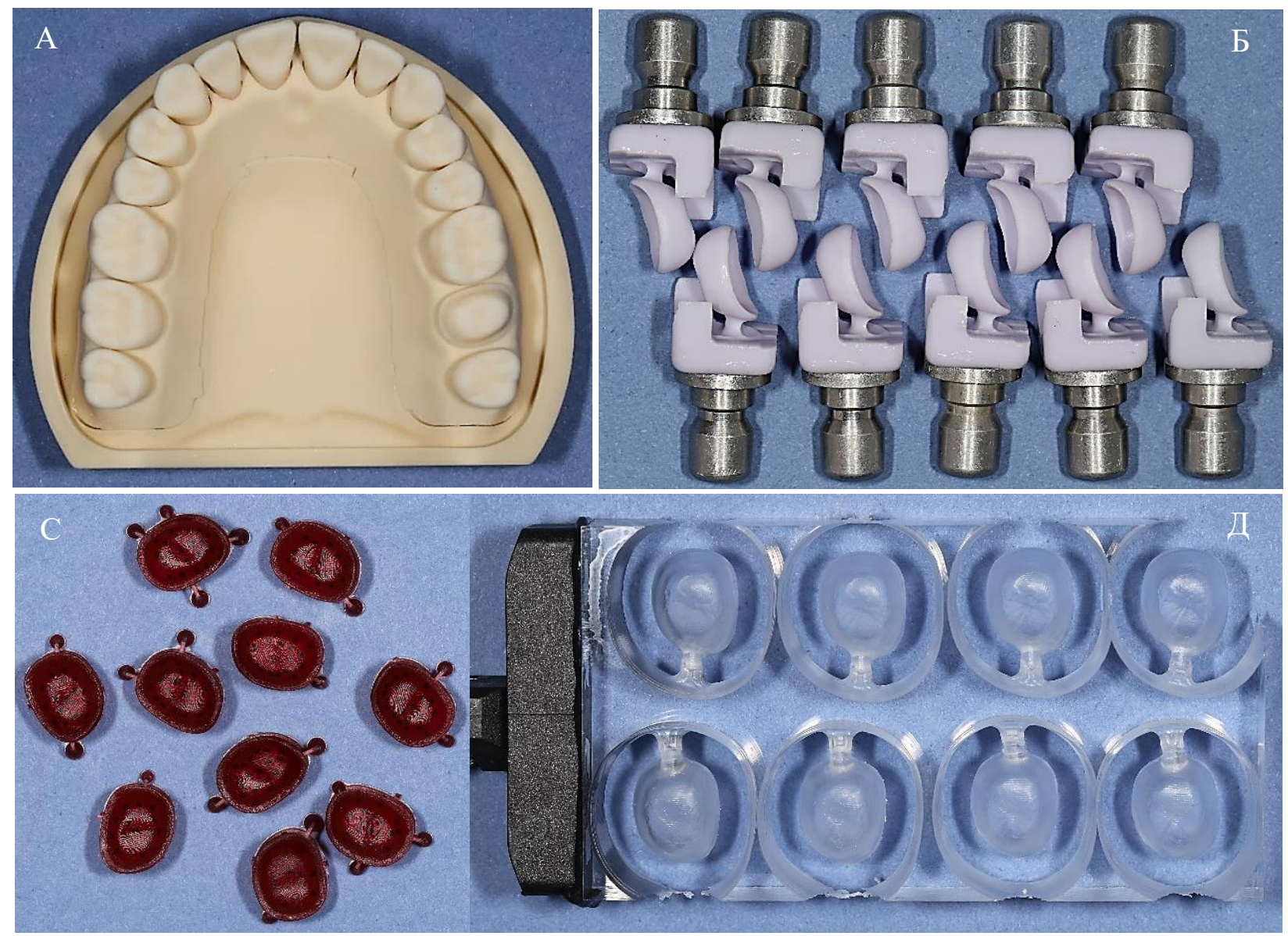

Рис. 2. а) экспериментальная модель; б) фрезерованные каркасы искусственных коронок из заготовок дисиликата лития E.max CAD; c) репродукции каркасов искусственных коронок, полученные с помощью 3D-принтера Asiga Max UV; д) фрезерованные репродукции каркасов искусственных коронок из заготовок беззольного полимерного материала KaVo ARCTICA C-Cast

Fig. 2. a) experimental model; b) milled frames of artificial crowns from billets of lithium disilicate E. max CAD; c) reproductions of frames of artificial crowns obtained using a 3D printer Asiga Max UV; d) milled reproductions of frames of artificial crowns from billets of ash-free polymer material KaVo ARCTICA C-Cast

Для оценки внутреннего прилегания полученных каркасов искусственных коронок была использована следующая методика. Каркасы заполняли корригирующим оттискным материалом Speedex light body, Coltene (Швейцария) и фиксировали на культю экспериментальной модели. По истечении времени, необходимого для полимеризации корригирующего оттискного материала, каркасы снимали с культи и извлекали силиконовый оттиск, отображающий качество внутреннего прилегания каркасов искусственных коронок. Далее силиконовую реплику гипсовали. Для каждого каркаса искусственной коронки получали два оттиска внутреннего прилегания. Одну реплику разрезали в мезио-дистальном, другую - в вестибуло-оральном направлении, получая тем самым 4 шлифа, отображающих внутреннее прилегание каркаса искусственной коронки. Затем с помощью операционного микроскопа Leica M320 под 40-кратным увеличением получали фотографии шлифов. В компьютерной программе Image J проводили измерения величины силиконовой реплики, отражающей плотность внутреннего прилегания каркасов искусственных коро- 
нок (рис. 3). На каждом шлифе проводили 10 измерений. Результаты измерений заносили в таблицы для последующего статистического анализа.
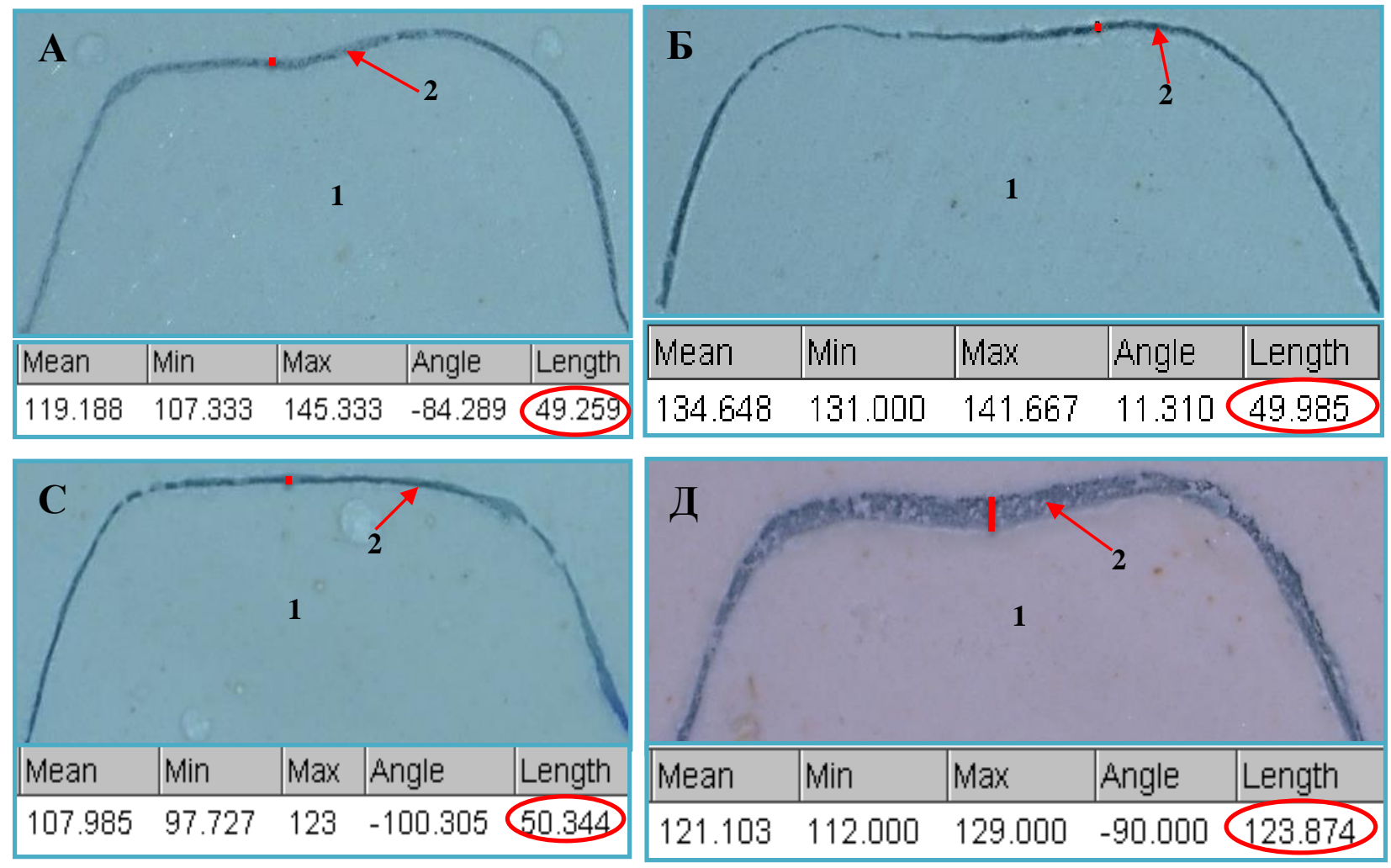

Рис. 3. Измерение величины цементного зазора каркасов искусственных коронок из дисиликата лития. 1 - гипс, 2 - силиконовая реплика. а) величина цементного зазора каркаса, изготовленного в CAD/CAM системе KaVo ARCTICA из заготовок E.max CAD - 49,259 мкм;

б) величина цементного зазора каркаса, изготовленного с применением 3D-принтера Asiga Max $\mathrm{UV},-49,985$ мкм; с) величина цементного зазора каркаса, изготовленного с применением беззольного полимерного материала KaVo ARCTICA C-Cast, - 50,3445 мкм; д) величина цементного зазора каркаса, изготовленного методом прессования, - 123,874 мкм

Fig. 3. Measurement of the cement gap of the frames of artificial crowns made of lithium disilicate. 1 - plaster, 2 - silicone replica. a) the Amount of cement gap frame, made in a CAD/CAM system from

KaVo ARCTICA blanks E. max CAD - 49,259 microns; b) the Size of the cement gap frame, manufactured using 3D printer Asiga Max UV - 49,985 microns; c) the Size of the cement gap frame, manufactured with the use of ashless polymeric material KaVo ARCTICA C-Cast - 50,3445 $\mu \mathrm{m}$; d) the Amount of cement gap frame, made of pressed - 123,874 $\mu \mathrm{m}$

При оценке внутреннего прилегания полученных каркасов искусственных коронок особое внимание уделяли величине цементного зазора, равномерности распределения корригирующего материала на поверхности культи, расположению края коронки на уступе культи 2.7 экспериментальной модели и необходимости припасовки каркаса коронки к культе зуба.

\section{Результаты исследования и их обсуждение}

Результаты по измерению величины цементного зазора каркасов искусственных коронок из дисиликата лития представлены в таблице 1. 
Таблица 1

Table 1

Средние величины цементного зазора каркасов искусственных коронок, изловленных разными методами, мкм ( $\mathrm{n}$ - количество каркасов искусственных коронок)

Average values of the cement gap of the frames of artificial crowns caught by different methods, microns ( $\mathrm{n}$ - the number of frames of artificial crowns)

\begin{tabular}{|c|c|c|c|c|}
\hline \multirow{2}{*}{$\mathrm{n}$} & \multicolumn{4}{|c|}{ Метод изготовления каркасов искусственных коронок } \\
\cline { 2 - 5 } & $\begin{array}{c}\text { KaVo ARCTICA } \\
\text { EMAX CAD }\end{array}$ & $\begin{array}{c}\text { КaVo ARCTICA } \\
\text { C-Cast }\end{array}$ & 3D-принтер ASIGA & $\begin{array}{c}\text { Традиционная технология } \\
\text { прессования }\end{array}$ \\
\hline 1 & 51,15 & 49,95 & 52,95 & 132,94 \\
\hline 2 & 47,59 & 50,72 & 51,54 & 109,66 \\
\hline 3 & 52,79 & 50,24 & 49,73 & 116,17 \\
\hline 4 & 50,72 & 51,63 & 49,58 & 14,89 \\
\hline 5 & 48,62 & 50,71 & 49,02 & 111,44 \\
\hline 6 & 47,72 & 49,58 & 49,01 & 107,31 \\
\hline 7 & 47,44 & 50,88 & 50,24 & 135,30 \\
\hline 8 & 47,96 & 50,92 & 49,80 & 118,78 \\
\hline 9 & 54,95 & 50,01 & 49,98 & 127,37 \\
\hline 10 & 51,09 & 50,75 & 50,85 & 120,68 \\
\hline Среднее & 50,00 & 50,54 & 50,27 & \\
значение & & & & \\
\hline
\end{tabular}

Описательные статистики (табл. 2) и визуальный анализ полученных нами данных с помощью гистограмм (рис. 4) позволяют качественно оценить характеристики распределения случайных величин. При этом мы получили возможность сделать вывод, что распределения значений признаков во всех группах отличаются от нормального (наблюдается ярко выраженная асимметрия). В связи с этим для анализа данных целесообразно было применение непараметрических статистических методов (Н-критерий Краскела - Уоллиса). В данном исследовании в качестве критического был принят уровень значимости $\mathrm{p}=0,05$.

Таблица 2

Table 2

Описательные статистики распределения значений величины цементного зазора

(n - количество каркасов искусственных коронок)

Descriptive statistics of the distribution of values of the cement gap

( $\mathrm{n}-$ the number of frames of artificial crowns)

\begin{tabular}{|c|c|c|c|c|c|c|c|c|c|}
\hline \multicolumn{2}{|c|}{$\begin{array}{c}\text { Метод } \\
\text { изготовления } \\
\text { каркасов } \\
\text { искусственных } \\
\text { коронок } \\
\end{array}$} & $\mathrm{n}$ & 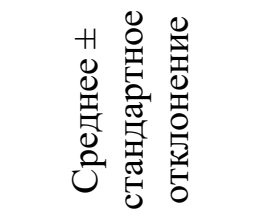 & 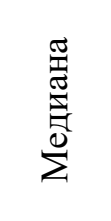 & $\sum_{\sum}^{\sum_{\Sigma}^{\Sigma}}$ & 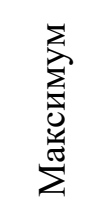 & 总 & 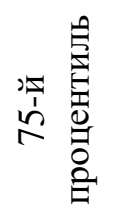 & $\begin{array}{c}\text { Стандартная } \\
\text { ошибка } \\
\text { среднего }\end{array}$ \\
\hline \multirow{2}{*}{$\begin{array}{l}\text { CAD/ } \\
\text { CAM } \\
\text { Arctica }\end{array}$} & $\begin{array}{l}\text { emax } \\
\text { CAD }\end{array}$ & 10 & $50 \pm 2,559$ & 49,67 & 47,44 & 54,95 & 47,78 & 51,13 & 0,8093 \\
\hline & $\begin{array}{c}\mathrm{C} \\
\text { Cast } \\
\end{array}$ & 10 & $50,54 \pm 0,5957$ & 50,72 & 49,58 & 51,63 & 50,07 & 50,85 & 0,1884 \\
\hline \multicolumn{2}{|c|}{$\begin{array}{l}\text { 3D-принтер } \\
\text { Asiga } \\
\end{array}$} & 10 & $50,27 \pm 1,218$ & 49,89 & 49,01 & 52,95 & 49,62 & 50,7 & 0,3852 \\
\hline \multicolumn{2}{|c|}{$\begin{array}{c}\text { Технология } \\
\text { прессования }\end{array}$} & 10 & $120,7 \pm 12,86$ & 117,5 & 105,9 & 141,9 & 110,1 & 131,5 & 4,066 \\
\hline \multicolumn{2}{|c|}{ Все методы } & 40 & $67,87 \pm 31,52$ & 50,8 & 47,44 & 141,9 & 49,78 & 67,69 & 4,983 \\
\hline
\end{tabular}




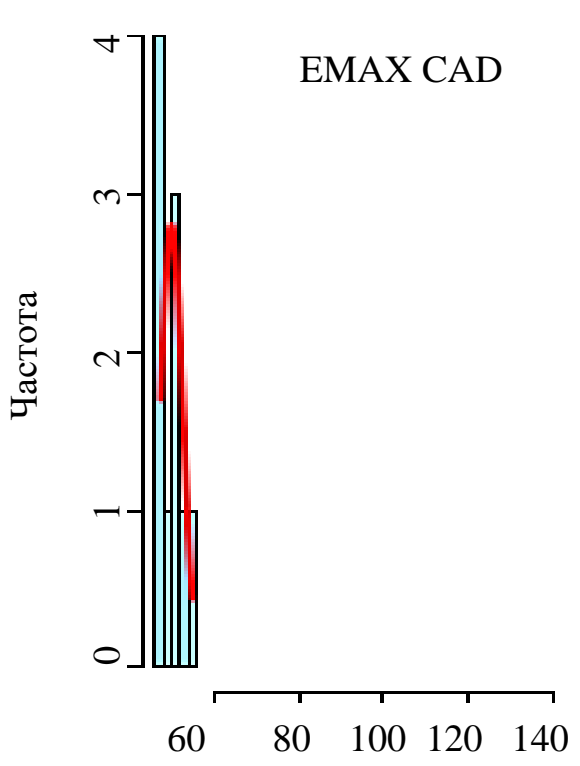

Величина цементного зазора, мкм

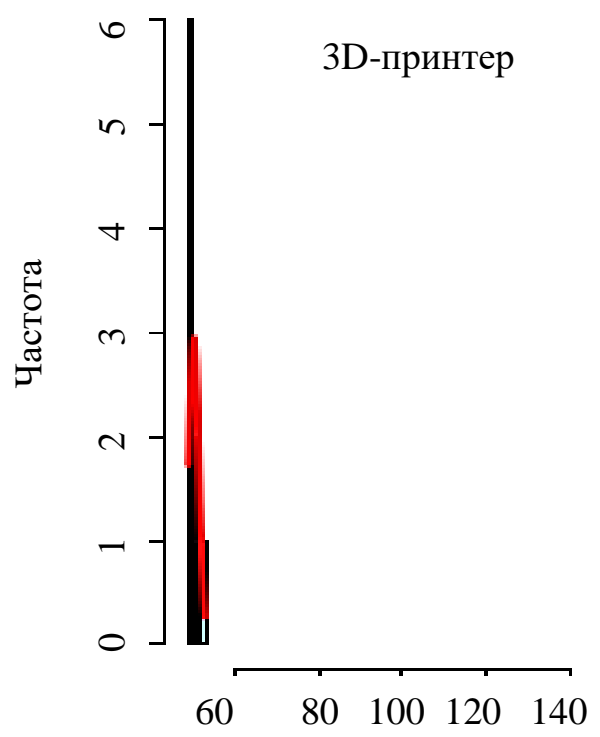

Величина цементного зазора, мкм

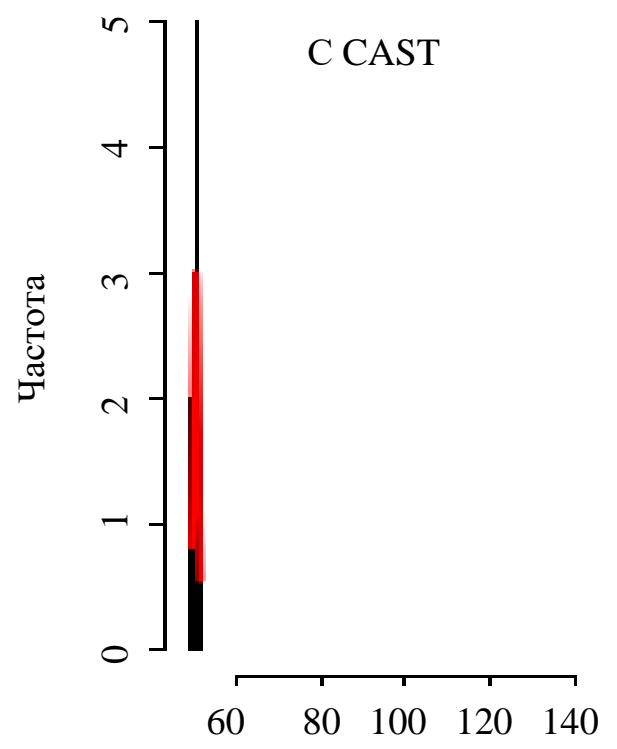

Величина цементного зазора, мкм

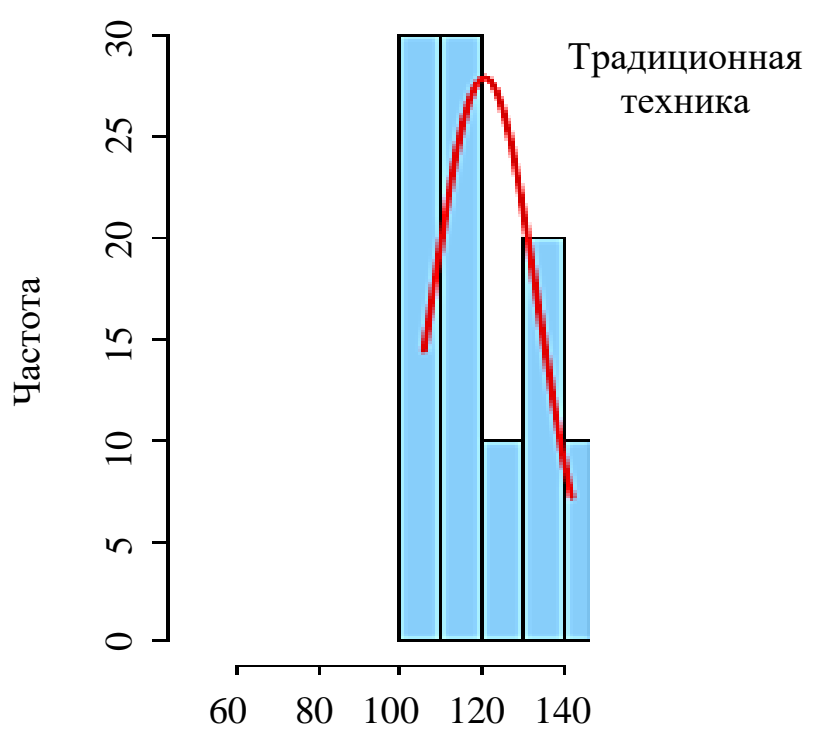

Величина цементного зазора, мкм

Рис. 4. Гистограммы распределения значений признака «Величина цементного зазора» Fig. 4. Histograms of the distribution of values of the «The size of the cement gap»

Нами было выявлено, что среднее значение величины цементного зазора между культей зуба и каркасом искусственной коронки из дисиликата лития, изготовленным в $\mathrm{CAD} / \mathrm{CAM}$ системе KaVo ARCTICA из заготовок Е.max CAD, составляет 50,00 $\pm 2,559$ мкм, из заготовок беззольного полимерного материала KaVo ARCTICA C-Cast $50,54 \pm 0,5957$ мкм. Среднее значение величины цементного зазора между культей зуба и каркасом искусственной коронки, изготовленным с применением 3D-принтера Asiga Max $\mathrm{UV}$, составляет 50,27 $\pm 1,218$ мкм. Среднее значение величины цементного зазора между культей зуба и каркасом искусственной коронки, изготовленным по традиционному методу прессования без использования цифровых технологий, составляет 120,70 $\pm 12,86$ мкм. На основании этих данных мы пришли к выводу, что величины цементного зазора каркасов искусственных коронок, изготовленных с помощью современных цифровых технологий (внутриротовое лазерное сканирование, CAD/CAM-система, 3D-принтер) и по традиционной технологии прессования, статистически различимы с уровнем значимости $\mathrm{p}<0,05$ (Н-критерий Краскела - Уоллиса $=22,529, \mathrm{p}=0,00005)$. 
Далее проводили попарное сравнение всех цифровых методик, применяемых для изготовления каркасов искусственных коронок из дисиликата лития, с традиционным методом прессования, применяя для статистического анализа W-критерий Манна - Уитни. В таблице 3 приведены значения критерия Манна - Уитни и соответствующие ему уровни значимости р для каждого признака для попарного сравнения групп.

Таблица 3

Table 3

Результаты сравнения цифровых методик изготовления каркасов искусственных коронок из дисиликата лития с традиционным методом прессования по признаку «Величина цементного зазора»

Results of comparison of digital methods for manufacturing artificial crown frames from lithium disilicate with the traditional method of pressing on the basis of «The size of the cement gap»

\begin{tabular}{|c|c|c|c|}
\hline \multicolumn{2}{|c|}{$\begin{array}{l}\text { Метод изготовления каркасов } \\
\text { искусственных коронок }\end{array}$} & W-критерий Манна - Уитни & $\mathrm{P}$ \\
\hline CAD/CAM & EMAX CAD & 0 & $0,00001^{* * *}$ \\
\cline { 2 - 4 } ARCTICA & C CAST & 0 & $0,00001^{* * *}$ \\
\hline \multicolumn{2}{|l|}{ 3D-принтер Asiga } & 0 & $0,00001^{* * *}$ \\
\hline
\end{tabular}
$\mathrm{p}<0,001$.

Примечание: *** - наличие статистически значимого различия на уровне значимости

Из таблицы видно, что все цифровые методики изготовления каркасов искусственных коронок из дисиликата лития различимы от традиционного метода прессования с уровнем значимости $\mathrm{p}<0,05$ по признаку «Величина цементного зазора».

На основании полученных данных мы пришли к выводу, что величина цементного зазора каркасов искусственных коронок, изготовленных в CAD/CAM системе $\mathrm{KaVo}$ ARCTICA из заготовок E.max CAD, в 2,37 раза меньше величины цементного зазора каркасов, полученных по традиционной технологии прессования. Величина цементного зазора каркасов искусственных коронок, изготовленных с применением $\mathrm{CAD} / \mathrm{CAM}$ системы KaVo ARCTICA из заготовок беззольного полимерного материала KaVo ARCTICA C-Cast, в 2,32 раза меньше величины цементного зазора каркасов, полученных по традиционной технологии прессования. Величина цементного зазора каркасов искусственных коронок, изготовленных с применением 3D-принтера Asiga Max $\mathrm{UV}$, в 2,36 раза меньше величины цементного зазора каркасов, полученных по традиционной технологии прессования.

Bce каркасы искусственных коронок, изготовленные с применением CAD/CAMсистемы KaVo ARCTICA и 3D-принтера Asiga Max UV, не нуждались в припасовке. Края каркасов искусственных коронок плотно прилегали к уступу культи 2.7 экспериментальной модели, зонд не застревал на стыке каркасов и культи в области придесневого уступа. Корригирующий материал равномерно распределялся на поверхности культи 2.7 при получении силиконовой реплики внутреннего прилегания каркасов искусственных коронок.

Края каркасов искусственных коронок, изготовленных по традиционной технологии прессования, ощущаются зондом при зондировании зоны придесневого уступа. 1 каркас искусственной коронки (10\%), изготовленный без применения цифровых технологий, нуждался в припасовке. Корригирующий материал неравномерно распределялся на поверхности культи 2.7 при получении силиконовой реплики внутреннего прилегания каркасов искусственных коронок.

Результаты изучения качества внутреннего прилегания каркасов искусственных коронок представлены в таблице 4. 
Результаты изучения внутреннего прилегания каркасов искусственных коронок The results of the study the internal fit of artificial crowns skeletons

\begin{tabular}{|c|c|c|c|c|}
\hline \multicolumn{2}{|c|}{$\begin{array}{c}\text { Метод изготовления } \\
\text { каркасов искусственных } \\
\text { коронок }\end{array}$} & $\begin{array}{c}\text { Цементный } \\
\text { зазор }\end{array}$ & $\begin{array}{c}\text { Необходимость } \\
\text { припасовки }\end{array}$ & $\begin{array}{c}\text { Равномерность пленки } \\
\text { корригирующего слоя на } \\
\text { всей поверхности культи }\end{array}$ \\
\hline \multirow{2}{*}{$\begin{array}{c}\text { CAD/CAM } \\
\text { ARCTICA }\end{array}$} & $\begin{array}{c}\text { EMAX } \\
\text { CAD }\end{array}$ & $50,00 \pm 2,559$ & Равномерно & $\begin{array}{c}\text { Плотное прилегание, } \\
\text { зонд не застревает }\end{array}$ \\
\cline { 2 - 5 } C CAST & $50,54 \pm 0,5957$ & Равномерно & $\begin{array}{c}\text { Плотное прилегание, } \\
\text { зонд не застревает }\end{array}$ \\
\hline \multicolumn{2}{|c|}{ 3D-принтер Asiga } & $50,27 \pm 1,218$ & Не нужно & $\begin{array}{c}\text { Плотное прилегание, } \\
\text { зонд не застревает }\end{array}$ \\
\hline \multicolumn{2}{|c|}{ Технология прессования } & $120,70 \pm 12,86$ & $\begin{array}{c}\text { Край коронки } \\
\text { в припасовке }\end{array}$ & ощущается зондом \\
\hline
\end{tabular}

В плане полученных результатов представляют интерес исследования иностранных авторов, занимающихся изучением данной проблемы. В частности, M. RevillaLeón et al. [2018] в своем исследовании по изучению внутреннего прилегания искусственных коронок, изготовленных из дисиликата лития, полученных с использованием цифровых технологий, пришли к выводу, что несъемные протезы, изготовленные аддитивным методом с помощью 3D-принтера, имели клинически приемлемые величины цементного зазора $(91,86 \pm 2,88$ мкм), которые существенно не отличались от средних величин цементного зазора искусственных коронок, изготовленных субтрактивным методом с помощью CAD/CAM-систем (96 $\pm 1,97$ мкм). Величина цементного зазора искусственных коронок, изготовленных по традиционной технологии прессования литьевой керамики, в данном исследовании составляла 80,62 $\pm 3,26$ мкм. На наш взгляд, различия в полученных результатах объясняются прежде всего тем, что авторами применялись разные CAD/CAM-системы и 3D-принтеры. Мы использовали для получения цифрового изображения экспериментальной модели внутриротовой сканер, зарубежные же авторы сканировали гипсовую модель, полученную по силиконовому оттиску экспериментальной модели, лабораторным сканером. Другие авторы (Shamseddine L. et al., 2017) при сравнении субтрактивного и аддитивного методов изготовления репродукций прессованных керамических искусственных коронок не обнаружили существенных различий между двумя данными методиками.

\section{Заключение}

Современные цифровые технологии, применяемые в ортопедической стоматологии (внутриротовое лазерное сканирование с помощью сканера iTero Cadent, CAD/CAM-система KaVo ARCTICA, 3D-принтер Asiga Max UV), позволяют изготавливать каркасы искусственных коронок из дисиликата лития с меньшей величиной цементного зазора и лучшим качеством внутреннего прилегания в отличие от каркасов, полученных с помощью традиционной технологии прессования литьевой керамики с уровнем значимости $\mathrm{p}<0,05$ (Н-критерий Краскела - Уоллиса $=22,529, \mathrm{p}=0,00005)$. На основании полученных данных мы пришли к выводу, что величина цементного зазора каркасов искусственных коронок, изготовленных в CAD/CAM системе KaVo ARCTICA из заготовок E.max CAD, в 2,37 раза меньше величины цементного зазора каркасов, полученных по традиционной технологии прессования с уровнем значимости $\mathrm{p}<0,05$.

Величина цементного зазора каркасов искусственных коронок, изготовленных с применением CAD/CAM системы KaVo ARCTICA из заготовок беззольного полимерного материала KaVo ARCTICA C-Cast, в 2,32 раза меньше величины цементного зазо- 
ра каркасов, полученных по традиционной технологии прессования с уровнем значимости $\mathrm{p}<0,05$. Величина цементного зазора каркасов искусственных коронок, изготовленных с применением 3D-принтера Asiga Max UV, в 2,36 раза меньше величины цементного зазора каркасов, полученных по традиционной технологии прессования с уровнем значимости $\mathrm{p}<0,05$.

\section{Список литературы}

1. Арутюнов С.Д., Бейтан А.В., Геворкян А.А., Цукор С.В., Комов Е.В. 2006. Оценка качества краевого прилегания несъемной конструкции зубного протеза. Институт стоматологии. 4: $42-44$.

2. Брикс О. 2014. Изумительная цельная керамика. М., Медицинская пресса: 292.

3. Вокулова Ю.А., Жулев Е.Н. 2016.Оценка точности получения оттисков зубных рядов с применением технологии лазерного сканирования. Современные проблемы науки и образования. № 5; URL: http://www.science-education.ru/ru/article/view?id=25447.

4. Вокулова Ю.А. 2017. Разработка и внедрение цифровых технологий при ортопедическом лечении с применением несъемных протезов зубов. Автореф. дис. ... кандидата медицинских наук. Нижний Новгород, 22.

5. Жулев Е.Н., Вокулова Ю.А. 2016. Изучение размерной точности цифровых оттисков, полученных с помощью внутриротового сканера iTero. Международный журнал прикладных и фундаментальных исследований. 12-2: 257-261. URL: https://appliedresearch.ru/ru/article/view?id=10818.

6. Жулев Е.Н., Вокулова Ю.А. 2017. Сравнительная оценка размерной точности оттисков в эксперименте. Dental Forum. 1: 38-42.

7. Карякин Н.Н., Горбатов Р.О. 2019. 3D-печать в медицине. М., ГЭОТАР-Медиа: 240.

8. Лебеденко И.Ю., Арутюнов С.Д., Ряховский А.Н. 2016. Ортопедическая стоматология: национальное руководство. М., ГЭОТАР-Медиа: 824.

9. Маркскорс Р. 2007. Несъемные стоматологические реставрации. М., Информационное агентство Newdent: 368.

10. Наумович С.С., Разоренов А.Н. 2016. САD/САМ системы в стоматологии: современное состояние и перспективы развития. Современная стоматология. 4: 2-9. пресс: 940.

11. Розенштиль С.Ф. 2010. Ортопедическое лечение несъемными протезами. М., Мед-

12. Ряховский А.Н. 2010. Цифровая стоматология. М., ООО «Авантис»: 282.

13. Смит Б., Хоу Л. 2010. Коронки и мостовидные протезы в ортопедической стоматологии. Пер. с англ.; под общ. ред. Е.Ю. Новикова. М., МЕДпресс-информ, 344 (Bernard G.N. Smith., Leslie C. Howe. 1998. Planning and making crowns and bridges. Informa healthcare, 344).

14. Цельнокерамические реставрации (сборник статей). 2010. М., ООО «Медицинская пресса»: 232.

15. Шустова В.А., Шустов М.А. 2016. Применение 3D-технологий в ортопедической стоматологии. СПб., СпецЛит: 159.

16. Dawood A., Sauret-Jackson V., Marti B., Darwood A. 2015. 3D printing in dentistry. Br. Dent. J., 219 (11): 521-529.

17. Massironi D., Pascetta R., Romeo G. 2007. Precision in dental esthetics. Clinical and laboratory procedures. Quintessence: 464.

18. Ng J., Ruse D., Wyatt C. 2014. A comparison of the marginal fit of crowns fabricated with digital and conventional methods. J. Prosthet. Dent., 112 (3): 555-560.

19. Revilla-León M., Olea-Vielba M., Esteso-Saiz A., Martínez-Klemm I., Özcan M. 2018. Marginal and Internal Gap of Handmade, Milled and 3D Printed Additive Manufactured Patterns for Pressed Lithium Disilicate Onlay Restorations. Eur. J. Prosthodont. Restor. Dent., 26 (1): 31-38. DOI: 10.1922/EJPRD_01733RevillaLeon08.

20. Shamseddine L., Mortada R., Rifai K., Chidiac J.J. 2017. Fit of pressed crowns fabricated from two CAD-CAM wax pattern process plans: A comparative in vitro study. J. Prosthet. Dent., 118 (1): 49-54. DOI:10.1016/j.prosdent.2016.10.003. 


\section{References}

1. Arutyunov S.D., Beitan A.V., Gevorkyan A.A., Tsukor S.V., Komov E.V. 2006. Otsenka kachestva kraevogo prileganiya nes"emnoi konstruktsii zubnogo proteza [Assessment of the quality of the edge fit of a fixed denture structure]. Institut stomatologii. 4: 42-44.

2. Briks O. 2014. Izumitel'naya tsel'naya keramika [Amazing one-piece ceramics]. M., Meditsinskaya pressa: 292.

3. Vokulova Y.A., Zhulev E.N. Otsenka tochnosti polucheniya ottiskov zubnykh ryadov s primeneniem tekhnologii lazernogo skanirovaniya [Evaluation of the accuracy of obtaining impressions of the dentition with the use of technology of laser scanning]. Modern problems of science and education. 2016; 5; URL: http://www.science-education.ru/ru/article/view?id=25447.

4. Vokulova Yu. A. 2017. Razrabotka i vnedrenie tsifrovykh tekhnologii pri ortopedicheskom lechenii s primeneniem nes"emnykh protezov zubov [Development and implementation of digital technologies in orthopedic treatment using fixed dentures]. Avtoref. dis. ... kandidata meditsinskikh nauk. Nizhnii Novgorod, 22.

5. Zhulev E.N., Vokulova Yu.A. 2016. Izuchenie razmernoi tochnosti tsifrovykh ottiskov, poluchennykh s pomoshch'yu vnutrirotovogo skanera iTero [Study of the dimensional accuracy of digital impressions obtained using the intraoral scanner iTero]. Mezhdunarodnyi zhurnal prikladnykh i fundamental'nykh issledovanii. 12-2: 257-261. URL: https://applied-research.ru/ru/article/view?id=10818.

6. Zhulev E.N., Vokulova Yu.A. 2017. Sravnitel'naya otsenka razmernoi tochnosti ottiskov v eksperimente [Comparative estimation of the dimensional accuracy of impressions in the experiment]. Dental Forum. 1: 38-42.

7. Karyakin N.N., Gorbatov R.O. 2019. 3D-pechat' v meditsine [3D printing in medicine]. M., GEOTAR-Media: 240.

8. Lebedenko I.Yu., Arutyunov S.D., Ryakhovskii A.N. 2016. Ortopedicheskaya stomatologiya: natsional'noe rukovodstvo [Prosthetic dentistry: a national guide]. M., GEOTAR-Media: 824.

9. Markskors R. 2007. Nes"emnye stomatologicheskie restavratsii [Non-removable dental restoration]. M., Informatsionnoe agentstvo Newdent: 368.

10. Naumovich S.S., Razorenov A.N. 2016. CAD/CAM sistemy v stomatologii: sovremennoe sostoyanie i perspektivy razvitiya [CAD/CAM systems in dentistry: current state and development prospects]. Sovremennaya stomatologiya. 4: 2-9.

11. Rozenshtil' S.F. 2010. Ortopedicheskoe lechenie nes"emnymi protezami [Orthopedic treatment with fixed prostheses]. M., Medpress: 940.

12. Ryakhovskii A.N. 2010. Tsifrovaya stomatologiya [Digital dentistry]. M., OOO «Avantis»: 282.

13. Smit B., Khou L. 2010. Koronki i mostovidnye protezy v ortopedicheskoi stomatologii [Planning and making crowns and bridges]. M., MEDpress-inform, 344 (Bernard G.N. Smith., Leslie C. Howe. 1998. Planning and making crowns and bridges. Informa healthcare, 344).

14. Tsel'nokeramicheskie restavratsii (sbornik statei) [All-ceramic restorations (collection of articles)]. 2010. M., OOO «Meditsinskaya pressa»: 232.

15. Shustova V.A. Shustov M.A. 2016. Primenenie 3D-tekhnologii v ortopedicheskoi stomatologii [Application of 3D technologies in orthopedic dentistry]. SPb., SpetsLit: 159.

16. Dawood A., Sauret-Jackson V., Marti B., Darwood A. 2015. 3D printing in dentistry. Br. Dent. J., 219 (11): 521-529.

17. Massironi D., Pascetta R., Romeo G. 2007. Precision in dental esthetics. Clinical and laboratory procedures. Quintessence: 464.

18. Ng J., Ruse D., Wyatt C. 2014. A comparison of the marginal fit of crowns fabricated with digital and conventional methods. J. Prosthet. Dent., 112 (3): 555-560.

19. Revilla-León M., Olea-Vielba M., Esteso-Saiz A., Martínez-Klemm I., Özcan M. 2018. Marginal and Internal Gap of Handmade, Milled and 3D Printed Additive Manufactured Patterns for Pressed Lithium Disilicate Onlay Restorations. Eur. J. Prosthodont. Restor. Dent., 26 (1): 31-38. DOI: 10.1922/EJPRD_01733RevillaLeon08.

20. Shamseddine L., Mortada R., Rifai K., Chidiac J.J. 2017. Fit of pressed crowns fabricated from two CAD-CAM wax pattern process plans: A comparative in vitro study. J. Prosthet. Dent., 118 (1): 49-54. DOI:10.1016/j.prosdent.2016.10.003. 


\section{Ссылка для цитирования статьи \\ Link for article citation}

Жулев Е.Н., Вокулова Ю.А. 2020. Изучение размерной точности внутреннего прилегания каркасов искусственных коронок из дисиликата лития, изготовленных с помощью традиционных и цифровых технологий. Актуальные проблемы медицины, 43 (2): 237-248. DOI 10.18413/2687-0940-2020-43-2-237-248.

Zhulev E.N., Vokulova Y.A. 2020. Study of the dimensional accuracy of the internal fit of the frames of artificial crowns made of lithium disilicate using traditional and digital technologies. Challenges in Modern Medicine, 43 (2): 237-248 (in Russian). DOI 10.18413/2687-0940-2020-43-2-237-248. 